\title{
Análise dos sistemas de certificação ambiental de edifícios residenciais no contexto brasileiro
}

\author{
Cristiane Bueno \\ Arquiteta e urbanista, doutoranda do Instituto de Arquitetura \\ e Urbanismo da Universidade de São Paulo (IAU-USP), Avenida \\ Trabalhador São-Carlense, 400, Centro, CEP 13560-960, São \\ Carlos, SP, (16) 33453898 / 981286432, cbueno@sc.usp.br

\section{João Adriano Rossignolo} \\ Engenheiro civil, professor associado da Faculdade de Zootecnia e \\ Engenharia de Alimentos da Universidade de São Paulo, Avenida \\ Duque de Caxias Norte, 225, Pirassununga, SP, CEP 13635-900, \\ rossignolo@usp.br
}

\section{Resumo}

As exigências de caráter ambiental para edifícios deram origem à criação de Sistemas de Certificação de Desempenho Ambiental de Edifícios, que vêm sendo usadas no cenário brasileiro, indiferentemente às suas especificidades e carências. O objetivo deste trabalho é promover uma análise das inadequações desses sistemas de certificação ao contexto brasileiro. A análise comparativa das certificações demonstrou uma série de itens avaliativos plenamente aplicáveis ao cenário brasileiro e outros que ainda necessitam de adaptações. Esta análise deverá servir como embasamento para a criação de diretrizes para o futuro desenvolvimento de um sistema de certificação ambiental de edificações habitacionais brasileiras.

Palavras-chave: certificação ambiental de habitações, conforto ambiental, eficiência energética. desenvolvimento sustentável, principalmente na sua dimensão ambiental, embasou a criação de um novo nicho imobiliário com amplas possibilidades de rentabilidade: os 'Edifícios Verdes', avaliados e rotulados a partir da criação de dezenas de Métodos de Avaliação de Desempenho Ambiental do Edifício, em diferentes países, com variados critérios e métodos de avaliação e certificação. Certificações como BREEAM (SKOPEK, 1997), GBTool (COLE e LARSSON, 2002) e LEED (USGBC, 2009) têm sido usadas para avaliar e certificar edifícios em grandes cidades do Brasil, por exemplo, onde seus critérios de avaliação e parâmetros avaliativos demonstram-se muitas vezes inadequados (PATRICIO e GOUVINHAS, 2004).

Os sistemas avaliativos de maior destaque no mercado contemporâneo referem-se majoritariamente à avaliação de edifícios corporativos e comerciais, sendo poucas as ferramentas disponíveis no mercado para avaliação da edificação de caráter habitacional, especificamente. O United States Green Building Council lançou, no início de 2008, o LEED for Homes (USGBC, 2008), o qual é direcionado apenas a edificações residenciais.

A criação da Certificação brasileira AQUA (Alta Qualidade Ambiental), pela Fundação Carlos Alberto Vanzolini em parceria com o Departamento de Engenharia de Produção da Escola Politécnica da Universidade de São Paulo e o Centre Scientifique et Technique du Bâtiment (CSTB), apresenta-se 
como um grande avanço nesse sentido, visto que toma em consideração problemáticas mais adequadas aos panoramas regionais brasileiros a serem analisados (FUNDAÇÃO CARLOS ALBERTO VANZOLINI, 2007).

A possibilidade de agregar o valor de tais ferramentas avaliativas à produção de edificações residenciais pode demonstrar-se muito proveitosa do ponto de vista do desenvolvimento de projetos de residências com melhores níveis de desempenho ambiental, através da análise de materiais, processos e sistemas, o que proporcionaria ao usuário a possibilidade de obtenção de conforto satisfatório com menor impacto ambiental.

Dentre os sistemas de certificação de desempenho ambiental de edifícios utilizados na atualidade alguns merecem destaque, por se tratarem dos sistemas de maior representatividade de aplicação internacionalmente, sendo eles GBTool, Green Globes, AQUA e LEED for Homes.

O GBTool (COLE e LARSSON, 2002) destaca-se por se tratar da primeira certificação que busca a flexibilidade e ponderação de pontuações de forma a ser adaptável às diferentes realidades regionais, ou seja, é a principal certificação com flexibilidade de aplicação internacional.

O Green Globes (SKOPEK e BRYAN, 2002) dentro de suas especificidades, torna-se representativo para estudo exatamente por ter sido criado como uma ferramenta de auto-avaliação online, ou seja, está disponível para que qualquer usuário possa avaliar o seu próprio edifício através do preenchimento de questionários pela internet.

A certificação AQUA (FUNDAÇÃO CARLOS ALBERTO VANZOLINI, 2007) é a primeira iniciativa de adaptação de um sistema de certificação para o contexto específico brasileiro, fato este que dá ao sistema grande representatividade e traz grande interesse para o estudo das especificidades regionais de seus critérios avaliativos.

Finalmente o sistema de certificação LEED for Homes (USGBC, 2008) trata-se da principal, iniciativa da atualidade para avaliação de desempenho ambiental de edificações habitacionais.
O sistema de certificação LEED que tem sido atualmente bastante aplicado em edifícios de escritórios no contexto brasileiro não tem seu formato e critérios adaptados para tal contexto, não obstante um esforço do USGBC em tornar o sistema mais flexível em sua versão 2009. Entretanto, esse sistema tem mantido-se como o principal sistema aplicado no contexto brasileiro devido ao seu grande reconhecimento mercadológico internacional. Por outro lado, o sistema AQUA, ainda que conte já com um esforço de adaptação ao contexto brasileiro, não tem se propagado largamente devido à dificuldade em obter-se informações e profissionais especializados em sua aplicação.

Nos últimos anos, diversas pesquisas nacionais abordaram a questão das certificações ambientais de edifícios. Piccoli et al (2010) realizou um estudo de caso analisando as peculiaridades no gerenciamento da construção de edifícios os quais estavam buscando alguma certificação ambiental e identificando atividades usuais, tradicionalmente realizadas sem nenhum interesse em obter selos ambientais, assim como novas atividades advindas das exigências impostas pelos sistemas de certificação. Esse autor usou como estratégia de pesquisa um estudo de caso realizado durante a fase de construção de um edifício comercial destinado a obter o selo de certificação LEED Gold. Os resultados mostraram que o sistema de certificação exigiu as mesmas atividades geralmente realizadas na fase de concepção, entretanto com um maior nível de envolvimento dos projetistas. $\mathrm{Na}$ fase de construção, além das crescentes exigências em atividades tradicionalmente desenvolvidas, novas atividades de gestão foram identificadas, bem como a necessidade de mais informações técnicas sobre os materiais de construção utilizados.

Vosgueritchian (2006), através de estudos dos sistemas de certificação BREEAM, GBTool, LEED, HQE, CASBEE, SPEAR e NABERS, teve como objetivo elucidar como tais sistemas abordam os impactos ambientais, assim como tecnologias relacionadas ao uso de energia, materiais e água.

Pardini (2009) analisou a aplicação do sistema de classificação LEED em projetos brasileiros, avaliando as características e restrições da certificação ao aplicá-la no contexto brasileiro, em geral. A pesquisa apresentou um estudo de caso comparativo da 
aplicação da certificação LEED nas realidades americana e brasileira e concluiu que alcançar os requisitos de certificação pode não ser uma tarefa fácil e que, no Brasil, muitas vezes significa saltar da completa ausência de referência para a tentativa de se atender padrões norte-americanos.

FOSSATI (2008) apresentou uma discussão comparativa metodológica dos sistemas de certificação LEED, BREEAM, GBTool, modelo proposto por Silva (2003), SBAT, CASBEE e $\mathrm{HQE}$, com base em critérios comparativos relacionados ao escopo e conteúdo avaliados pelas certificações, parâmetros de desempenho, pontuação, ponderação, divulgação dos resultados e classificação final do edifício.

Outra iniciativa importante para a avaliação ambiental de edifícios de habitação é o Selo Casa Azul (CAIXA ECONÔMICA FEDERAL, 2010). O método utilizado pelo banco brasileiro Caixa Econômica Federal para a concessão do selo baseia-se na verificação, durante a análise da viabilidade técnica do projeto, da conformidade com os critérios estabelecidos pelo instrumento, que estimula a adoção de práticas voltadas para a sustentabilidade de projetos habitacionais. Tais práticas são avaliadas por categorias relacionadas à qualidade urbana, projeto e conforto, eficiência energética, conservação de recursos materiais, gestão da água e práticas sociais. Esse rótulo não foi considerado para fins de avaliação ou comparação nesta pesquisa, uma vez que ainda é uma ferramenta de uso restrito, principalmente aplicado a projetos habitacionais apresentados à Caixa Econômica Federal para pedidos de financiamento ou em programas de transferência, e apenas as empresas de construção, o governo, as empresas públicas de habitação, cooperativas, associações e entidades representativas de movimentos sociais podem se inscrever para o selo, não sendo tal ferramenta avaliativa aberta ao uso público.

O objetivo desta pesquisa é, através da análise comparativa de sistemas pré-selecionados de certificação de desempenho ambiental de edificações, obter um panorama geral de suas inadequações ao contexto habitacional brasileiro e procurar, assim, possibilidades de adaptação de tais pontos, de forma a criar embasamento para o futuro desenvolvimento de um sistema nacional de certificação ambiental de edificações habitacionais. O desenvolvimento de um 'selo' de desempenho ambiental para edificações residenciais possibilitará a elevação dos níveis de exigência de qualidade projetual, buscando a melhoria de qualidade técnica e conforto ambiental oferecidos ao usuário, assim como a redução do impacto ambiental ocasionado pela construção e operação de tais edificações.

É importante salientar neste ponto, que os métodos de avaliação do edifício a serem estudados neste trabalham tratam, principalmente, da avaliação das interações do edifício com o meio ambiente através de suas necessidades de consumo e geração de resíduos, as entradas e saídas de seu ciclo de vida em todas as suas fases, de projeto, construção, operação e desativação. Portanto, este a pesquisa contida neste artigo trata de um recorte relativo ao desempenho ambiental de edifícios, considerando-se apenas parcialmente o conceito de sustentabilidade, com enfoque puramente ambiental, ou seja, avaliando e gerindo tão somente as interferências do edifício no meio natural, ótica que compreende principalmente as vertentes ambientais do desenvolvimento sustentável, e apenas algumas de suas interfaces com as vertentes econômica, social, cultural e antrópica.

\section{Metodologia de análise dos sistemas de certificação}

De acordo com o objetivo deste trabalho, os procedimentos metodológicos utilizados podem ser divididos em três etapas principais, sendo elas:

Classificação dos sistemas de certificação existentes:

Análises comparativas entre os sistemas de certificação ambiental existentes, balizadas por categorias e critérios específicos estabelecidos;

Discussão das inadequações encontradas na análise comparativa dos sistemas de certificação e proposição de alternativas para adaptação.

\section{Classificação}

Na etapa de Classificação dos sistemas de certificação de desempenho ambiental existentes pretendeu-se montar um quadro geral dos sistemas de certificação 
de desempenho ambiental, classificando-os de acordo com os seguintes parâmetros:

Critérios de Avaliação: descrição das categorias nas quais os sistemas estão subdivididos;

Contexto de criação: especificação do contexto para o qual cada um dos sistemas foi desenvolvido;

Metodologia de avaliação: determinação da metodologia utilizada pelo sistema para análise das informações sobre o edifício a ser avaliado e os instrumentos empregados para avaliação (checklist, questionário, comparativa);

Complexidade de aplicação: determinação do nível de complexidade de aplicação do sistema, simples ou complexa, e se é passível de ser aplicada pelo usuário ordinário ou necessita de aplicadores especializados, ou seja, definição da usabilidade da ferramenta;

Sistema de classificação: descrição da forma de saída dos resultados da avaliação, que pode ser através da rotulação do edifício, ou relatório de melhorias a serem realizadas.

Depois de realizada a classificação dos sistemas, através de um quadro sintético destes, passaremos então à etapa de análise comparativa dos sistemas, de acordo com metodologia descrita à seguir.

\section{Análise comparativa}

A análise comparativa dos sistemas de avaliação de desempenho ambiental estudados foi realizada através do estabelecimento de categorias avaliativas, as quais, ao serem comparadas, buscaram uniformizar a metodologia de avaliação. A partir do levantamento de cada sistema estudado, foram determinadas as categorias para avaliação comparativa:

Processo de projeto;

Conexões;

Implantação;

Consumo de recursos;

Emissões;

Conforto e qualidade ambiental;

Serviços;

Aspectos econômicos;

Planejamento de operação.
Dentro de cada uma dessas categorias, para cada sistema de certificação estudado, há uma série de créditos, os quais desenvolvem a análise do edifício de acordo com temáticas variadas, as quais variam bastante nos diferentes sistemas. A fase de balizamento das categorias selecionadas foi realizada a partir da dilaceração dos critérios avaliativos de cada sistema para cada categoria da lista acima, os quais foram analisados com base em critérios pré-definidos, contrapostos às tais créditos para verificar-se: A) sua total adequação, B) inadequação de parâmetros, com possibilidade de adaptação, C) inadequação regional, com possibilidade de tornar o crédito em questão de cumprimento optativo, ou D) inadequação conceitual sem possibilidades de adaptação, conforme modelo proposto na Tabela 01.

Os critérios para balizamento das categorias estão apresentados abaixo, juntamente com uma descrição de sua aplicação:

Adequação dos créditos de cada categoria à normatização nacional: os índices de desempenho mínimos exigidos pelos sistemas de certificação devem ser iguais ou superiores àqueles presentes na normatização brasileira;

- Aplicabilidade dos créditos da categoria estudada no contexto brasileiro: os temas abordados nos créditos, assim como os níveis de desempenho exigidos, devem ser compatíveis com a realidade brasileira, no que toca questões ligadas à geografia, clima, cultura, economia, uso de energia e técnicas e práticas construtivas;

. Pertinência para a determinação do desempenho ambiental do edifício: as questões abordadas pelos sistemas de certificação estudados devem estar diretamente relacionadas com a melhoria de desempenho ambiental do edifício, considerandose as questões que o constituem;

. Flexibilidade regional: os temas abordados pelos sistemas de certificação, assim como seus níveis de desempenho exigidos devem ser flexíveis para adaptação às diferentes realidades regionais brasileiras.

Quando, nessa etapa de balizamento da análise comparativa, algum critério de determinada categoria de avaliação foi indicado como "B", essa indicação não desqualifica totalmente a possibilidade de 


\begin{tabular}{|c|c|c|c|c|}
\hline \multirow[b]{2}{*}{$\begin{array}{l}\text { Créditos das } \\
\text { Categorias de } \\
\text { Avaliação }\end{array}$} & \multicolumn{4}{|c|}{ Critérios para balizamento das Categorias dos Sistemas de Certificação } \\
\hline & $\begin{array}{c}\text { Adequação à } \\
\text { normatização } \\
\text { estudada }\end{array}$ & $\begin{array}{l}\text { Aplicabilidade no } \\
\text { contexto } \\
\text { brasileiro }\end{array}$ & $\begin{array}{l}\text { Pertinência para a } \\
\text { determinação de } \\
\text { desempenho } \\
\text { ambiental }\end{array}$ & $\begin{array}{l}\text { Flexibilidade } \\
\text { regional }\end{array}$ \\
\hline Processo de Projeto & $\mathrm{A} / \mathrm{B} / \mathrm{C} / \mathrm{D}$ & $\mathrm{A} / \mathrm{B} / \mathrm{C} / \mathrm{D}$ & $A / B / C / D$ & $\mathrm{~A} / \mathrm{B} / \mathrm{C} / \mathrm{D}$ \\
\hline Conexões & $\mathrm{A} / \mathrm{B} / \mathrm{C} / \mathrm{D}$ & $\mathrm{A} / \mathrm{B} / \mathrm{C} / \mathrm{D}$ & $\mathrm{A} / \mathrm{B} / \mathrm{C} / \mathrm{D}$ & $\mathrm{A} / \mathrm{B} / \mathrm{C} / \mathrm{D}$ \\
\hline Implantação & $\mathrm{A} / \mathrm{B} / \mathrm{C} / \mathrm{D}$ & $\mathrm{A} / \mathrm{B} / \mathrm{C} / \mathrm{D}$ & $\mathrm{A} / \mathrm{B} / \mathrm{C} / \mathrm{D}$ & $\mathrm{A} / \mathrm{B} / \mathrm{C} / \mathrm{D}$ \\
\hline Consumo de Recursos & $A / B / C / D$ & $\mathrm{~A} / \mathrm{B} / \mathrm{C} / \mathrm{D}$ & $\mathrm{A} / \mathrm{B} / \mathrm{C} / \mathrm{D}$ & $\mathrm{A} / \mathrm{B} / \mathrm{C} / \mathrm{D}$ \\
\hline Emissões & $\mathrm{A} / \mathrm{B} / \mathrm{C} / \mathrm{D}$ & $\mathrm{A} / \mathrm{B} / \mathrm{C} / \mathrm{D}$ & $\mathrm{A} / \mathrm{B} / \mathrm{C} / \mathrm{D}$ & $\mathrm{A} / \mathrm{B} / \mathrm{C} / \mathrm{D}$ \\
\hline $\begin{array}{l}\text { Conforto e Qualidade } \\
\text { Ambiental }\end{array}$ & $\mathrm{A} / \mathrm{B} / \mathrm{C} / \mathrm{D}$ & $\mathrm{A} / \mathrm{B} / \mathrm{C} / \mathrm{D}$ & $\mathrm{A} / \mathrm{B} / \mathrm{C} / \mathrm{D}$ & $\mathrm{A} / \mathrm{B} / \mathrm{C} / \mathrm{D}$ \\
\hline Serviços & $\mathrm{A} / \mathrm{B} / \mathrm{C} / \mathrm{D}$ & $\mathrm{A} / \mathrm{B} / \mathrm{C} / \mathrm{D}$ & $\mathrm{A} / \mathrm{B} / \mathrm{C} / \mathrm{D}$ & $\mathrm{A} / \mathrm{B} / \mathrm{C} / \mathrm{D}$ \\
\hline Aspectos Econômicos & $\mathrm{A} / \mathrm{B} / \mathrm{C} / \mathrm{D}$ & $\mathrm{A} / \mathrm{B} / \mathrm{C} / \mathrm{D}$ & $\mathrm{A} / \mathrm{B} / \mathrm{C} / \mathrm{D}$ & $\mathrm{A} / \mathrm{B} / \mathrm{C} / \mathrm{D}$ \\
\hline $\begin{array}{l}\text { Planejamento de } \\
\text { operação }\end{array}$ & $\mathrm{A} / \mathrm{B} / \mathrm{C} / \mathrm{D}$ & $\mathrm{A} / \mathrm{B} / \mathrm{C} / \mathrm{D}$ & $\mathrm{A} / \mathrm{B} / \mathrm{C} / \mathrm{D}$ & $A / B / C / D$ \\
\hline
\end{tabular}

Figura 1: Tabela 01 - Critérios para Análise Comparativa de Sistemas de Certificação. Fonte: Autores. aplicação de tal critério, e significa apenas algum tipo de divergência em seus parâmetros avaliativos. Por tal motivo, acompanhando cada uma das tabelas de balizamento, em todas as categorias avaliadas, foi realizada também uma análise descritiva das inadequações de cada critério e suas possibilidades de adaptação.

Outros créditos classificados como "C", são aqueles que podem, de forma diversa, tornar-se opcionais, ou seja, que poderiam tornar-se de cumprimento opcional num sistema de certificação adaptado para aplicação no contexto brasileiro, devido ao seu caráter regional, específico ou complementar, funcionando como pontuação extra, relativa a características regionais do projeto, ou com ponderação do seu valor final na avaliação e classificação do edifício.

Dentre os créditos classificados como inadequados " $D$ ", podem existir também aqueles que poderão ser considerados como alternativos, ou seja, que já possuem cumprimento opcional em seus sistemas de certificação de origem, e poderiam ser simplesmente excluídos de um sistema adaptado ao contexto brasileiro, sem acarretar prejuízos para a estrutura avaliativa.
É importante ressaltar, neste ponto, que, apesar de um dos critérios de balizamento abordar a adequação à legislação brasileira, este se refere apenas àquelas situações em que existe uma normatização adequada, e esta está em conflito com os parâmetros de desempenho requeridos pelo sistema de certificação. Na maior parte dos casos, neste estudo, a falta de documentos normativos brasileiros relacionados a parâmetros de desempenho tornam as exigências das certificações mais fáceis de serem aplicadas, e não representam um impedimento real para a aplicação de um sistema de certificação.

\section{Discussão das inadequações}

A terceira etapa deste trabalho consistiu na organização das informações obtidas na fase anterior de forma a construir um cenário das inadequações de aplicação dos sistemas de certificação estudados no contexto brasileiro, para se estabelecer uma discussão das possibilidades de adaptação de tais critérios avaliativos inadequados, para o aprimoramento de um método avaliativo de desempenho ambiental aplicável no contexto brasileiro, e para edificações de caráter habitacional. 


\section{Classificação e análise comparativa das certificações}

Inicialmente realizou-se uma análise conjunta das principais características de operação de cada sistema de certificação estudado, considerando critérios de avaliação, aplicabilidade, metodologia de avaliação, complexidade de aplicação e sistema de classificação (Tabela 02).

A discussão de aplicabilidade, neste trabalho, demonstrou estar fortemente associada às questões de complexidade das ferramentas, assim como à sua flexibilidade regional, ou seja, uma ferramenta pode ser amplamente aplicada por sua flexibilidade de critérios, mas ainda assim, se sua metodologia for muito complexa, a sua aplicabilidade fica comprometida. Esse é o caso do GBTool, por exemplo. Esta metodologia foi desenvolvida para ter critérios e ponderação flexíveis, entretanto, a sua complexidade acaba por restringir sua aplicação no processo projetual, limitando o seu uso à pesquisa científica. Por outro lado, sistemas avaliativos de aplicação simplificada na forma de checklist ou questionário, como LEED e Green Globes, respectivamente, apesar do atrativo da simplicidade de utilização, são desenvolvidos para os contextos nacionais específicos dos Estados Unidos e Canadá, o que limita o seu uso em diferentes países, como o Brasil, por não apresentarem capacidade suficiente de adaptação a diferentes contextos locais.

O caso do AQUA, do ponto de vista da aplicabilidade, apresenta nuances bastante específicas, uma vez que sua estruturação em questionário aplicado por terceiros, e sua adaptação ao contexto brasileiro deveriam tornar esse o método mais fortemente aplicado no panorama atual. Entretanto, a falta de divulgação em torno dessa certificação, combinada com os altos custos do processo tem, até o presente momento, tornado sua representatividade de aplicação extremamente frágil.
Figura 2: Tabela 02 - Classificação dos sistemas de certificação. Fonte: Autores.

\begin{tabular}{ll}
\hline LEED for Homes & GBTool \\
\hline Janeiro, 2008 & Fevereiro, 2002 \\
\hline Sítios Sustentáveis; & Utilização de Recursos; \\
Eficiência de Água; & Cargas Ambientais; \\
Energia e Atmosfera; & Qualidade Ambiental \\
Materiais e Recursos; & Interna; \\
Qualidade do Ar; & Qualidade dos serviços; \\
Interno; & Aspectos Econômicos; \\
Inovação em Projeto; & Gestão; \\
Prioridade Regional; & Transporte. \\
Desenvolvido para & Pode ser aplicado em \\
aplicação no contexto & qualquer local, devido à \\
norte-americano. & flexibilidade de critérios \\
& e ponderações.
\end{tabular}

\section{Green Globes}

Dezembro, 2004

Poluição;

Energia;

Água;

Qualidade Ambiental

Interna;

Gerenciamento do Meio

Ambiente;

Recursos.

Desenvolvido para aplicação no contexto canadense.

\section{AQUA}

Outubro, 2007

Eco-construção;

Gestão;

Conforto;

Saúde.

Adaptado para aplicação no contexto brasileiro.
Comparação do edifício avaliado com edifício considerado referência quanto às práticas ambientais locais. A avaliação é estruturada em 04 níveis hierárquicos de desempenho: questões, categorias, critérios e sub-critérios

Aplicação complexa, comparativa, mais indicada para pesquisas científicas.

Insatisfatório; Mínimo Aceitável; Intermediário: Excelente.
A inscrição é feita pela internet e o edifício a ser avaliado é conduzido ao AUDIT on-line. É preenchido um questionário sobre as categorias e subcategorias. O resultado é um relatório com a avaliação final.

Aplicação simples, no formato de questionário de fácil preenchimento.

Um relatório das questões que precisam de melhorias é enviado aos usuários.
A avaliação da dá-se de maneira evolutiva ao longo da estrutura em árvore composta de Categorias, Subcategorias e Preocupações, às quais se avalia pelos conceitos Bom, Superior ou Excelente.

Aplicação na forma de questionário, aplicado por equipe consultora.

Bom;

Superior;

Excelente.
Prata;

Platina. 
Figura 3: Tabela 03 - Categorias para Análise Comparativa de Sistemas de Certificação. Fonte: Autores.
As metodologias de avaliação são as principais forças contribuintes para a complexidade de aplicação de um sistema. LEED, Green Globes e AQUA, estruturam-se em forma de checklist (para o primeiro) ou questionário, determinando assim, sua baixa complexidade de aplicação. Neste ponto, cabe destacar a característica auto-avaliativa do Green Globes, no qual todo o processo é feito online, conferindo a esta metodologia um caráter prático e inovador. O GBTool, diferentemente, aborda as questões relativas ao edifício de acordo com quatro diferentes níveis hierárquicos, sempre estabelecendo uma comparação com um edifício considerado referência, o que torna essa estrutura avaliativa bastante complexa.

Finalmente, os sistemas de classificação apresentados pelos métodos também trazem uma certa regularidade, tendo a maioria deles uma estrutura de rotulação, a qual confere ao edifício um título de "mais" ou "menos sustentável". Aqui, apenas o Green Globes diferencia-se, fornecendo, ao final da avaliação, não um rótulo, mas um relatório de avaliação indicando em que pontos podem ser realizadas melhorias no projeto do edifício.

O que podemos concluir através desta análise é que a adaptação de um único método existente às especificidades regionais de um país, apesar de consistir numa alternativa viável, talvez ainda não seja a alternativa mais eficiente, do ponto de vista da criação de um sistema o qual não apenas certifique e rotule, mas que realmente avalie o desempenho ambiental das edificações.

Para facilitar a realização de tal análise comparativa foi realizada a subdivisão dos sistemas estudados de acordo com um grupo de categorias preestabelecidas nos procedimentos metodológicos, de acordo com a Tabela 03

\begin{tabular}{|c|c|c|c|c|}
\hline \multirow{2}{*}{$\begin{array}{l}\text { Categorias de } \\
\text { Avaliação }\end{array}$} & \multicolumn{4}{|c|}{ Categorias a serem comparadas por Sistema de Certificação } \\
\hline & Green Globes & AQUA & LEEDfor Homes & Green Glokes \\
\hline $\begin{array}{l}\text { Processo de } \\
\text { Projeto }\end{array}$ & & $\begin{array}{l}\text { - Gestão de } \\
\text { projeto }\end{array}$ & $\begin{array}{l}\text { - Escolha integrada de } \\
\text { produtos, sistemas, } \\
\text { processos construtivos }\end{array}$ & $\begin{array}{l}\text { - Inovação e } \\
\text { Processo de Projeto }\end{array}$ \\
\hline Conexões & $\begin{array}{l}\text { - Transportes } \\
\text { Diários }\end{array}$ & & $\begin{array}{l}\text { - Relação do edifício } \\
\text { com o seu entorno }\end{array}$ & $\begin{array}{c}\text { - Localização e } \\
\text { Ligações }\end{array}$ \\
\hline Implantação & & - Terreno & & - Sítios Sustentáveis \\
\hline $\begin{array}{l}\text { Consumo de } \\
\text { Recursos }\end{array}$ & $\begin{array}{l}\text { - Consumo de } \\
\text { Recursos }\end{array}$ & $\begin{array}{l}\text { - Energia } \\
\text { - Água } \\
\text { - Recursos }\end{array}$ & $\begin{array}{l}\text { - Gestão de energia } \\
\text { - Gestão da água } \\
\text { - Escolha integrada de } \\
\text { produtos, sistemas, } \\
\text { processos construtivos }\end{array}$ & $\begin{array}{l}\text { - Eficiência de Água } \\
\text { - Materiais } \\
\text { eRecursos } \\
\text { - Energia e } \\
\text { Atmosfera }\end{array}$ \\
\hline Emissões & $\begin{array}{l}\text { - Cargas } \\
\text { Ambientais }\end{array}$ & $\begin{array}{l}\text { - Emissões, } \\
\text { efluentes e } \\
\text { outros impactos }\end{array}$ & $\begin{array}{l}\text { - Gestão dos resíduos de } \\
\text { uso e operação do } \\
\text { edifício }\end{array}$ & $\begin{array}{l}\text { - Energia e } \\
\text { Atmosfera }\end{array}$ \\
\hline $\begin{array}{l}\text { Conforto e } \\
\text { Qualidade } \\
\text { Ambiental }\end{array}$ & $\begin{array}{l}\text { - Qualidade } \\
\text { Ambiental } \\
\text { Interna }\end{array}$ & $\begin{array}{l}\text { - Ambiente } \\
\text { interno }\end{array}$ & $\begin{array}{l}\text { - Conforto higrotérmico } \\
\text { - Conforto acústico } \\
\text { - Conforto visual } \\
\text { - Conforto olfativo } \\
\text { - Qualidade sanitária dos } \\
\text { ambientes, do ar e da } \\
\text { água }\end{array}$ & $\begin{array}{l}\text { - Qualidade do } \\
\text { Ambiente Interno }\end{array}$ \\
\hline Serviços & $\begin{array}{l}\text { - Qualidade do } \\
\text { Serviço }\end{array}$ & & & \\
\hline $\begin{array}{l}\text { Aspectos } \\
\text { Econômicos }\end{array}$ & - Economia & & & \\
\hline $\begin{array}{l}\text { Planejamento de } \\
\text { operação }\end{array}$ & - Gerenciamento & & $\begin{array}{l}\text { - Canteiro de obras com } \\
\text { baixo impacto ambiental } \\
\text { - Manutenção - } \\
\text { Permanência do } \\
\text { desempenho ambiental }\end{array}$ & $\begin{array}{l}\text { - Conscientização e } \\
\text { Educação }\end{array}$ \\
\hline
\end{tabular}


A Tabela 04 apresenta todos os créditos avaliados dentre os sistemas de certificação estudados os quais apresentam algum tipo de inadequação em relação aos critérios de balizamento, inadequações essas encontradas no estudo de análise comparativa, as quais estão ordenadas por categoria de avaliação.

A primeira categoria de análise dos sistemas, referente a Processos de Projeto, é sem dúvida a detentora de maior flexibilidade em todas as certificações estudadas e, portanto, passível de ser aplicada nos mais diferentes contextos devido ao seu caráter abrangente e receptivo na busca de inovações e características regionais em cada projeto de forma particular, tratando de critérios mais subjetivos e, portanto, mais facilmente ampliáveis ao contexto global.

A categoria Conexões aborda a questão das conexões do edifício com a infraestrutura urbana na qual está inserido, e se configura como claramente pertinente para determinação de desempenho ambiental deste, uma vez consideradas as características de consumo de recursos e emissões de poluentes relacionadas aos meios de transporte necessários para os seus usuários, assim como à criação de infraestrutura urbana de água, esgoto e energia.

$\mathrm{Na}$ conceituação dos sistemas de certificação estudados os parâmetros avaliativos relacionados a tais questões deveriam ser detentores de destaque. Entretanto, nota-se a ausência ou pouca notoriedade de tais critérios, sendo até mesmo, inexistentes em alguns sistemas, como é o caso do Green Globes, ou muito incipientes, como no caso do GBTool.

A avaliação dos tópicos dedicados à temática das conexões demonstra também uma grande facilidade de adaptação desses itens, em todas as certificações estudadas, ao cenário brasileiro, seja da forma como foram concebidos ou com pequenas modificações.

A categoria Implantação refere-se a todas as questões ligadas à escolha e tratamento do terreno, antes, durante e depois da construção, abrangendo questões como remediação do solo, densidade construtiva, controle de erosão, efeitos de ilha de calor e gerenciamento de águas de chuva, entre outros. Tais itens apresentam, quase que invariavelmente, um caráter flexível, sendo passíveis de aplicação em variadas realidades regionais, e com parâmetros de desempenho medianos, ou seja, com níveis de exigência moderados. Dentre todos os sistemas de certificação estudados os únicos que apresentam possibilidades de avaliação das questões ligadas ao terreno são o Green Globes e o LEED for Homes.

O crédito "Efeito Local de Ilha de Calor", na categoria Sítios Sustentáveis, demonstra restrição regional de aplicação, quando aconselha o plantio de vegetação para sombreamento de pelo menos 50\% das áreas abertas para o dia 21 de junho, com sol a pino, demonstrando-se claramente direcionada a habitações localizadas no hemisfério norte, onde tal data trata-se do solstício de verão. Dentro da mesma categoria, ainda, o crédito referente ao "Controle não-tóxico de pestes", traz uma série de recomendações quanto a construções em madeira, as quais não são largamente comuns no contexto geral brasileiro, a não ser por algumas exceções regionais, principalmente na região sul do país. O item "Desenvolvimento compacto" mostra-se inadequado à legislação vigente, mas é importante esclarecer que não se trata de uma incompatibilidade rígida, ou seja, a adequação fica dependente dos zoneamentos urbanos locais, e sua densidade construtiva máxima permitida.

A temática referente ao consumo de recursos é uma das mais amplamente abordadas nos sistemas de avaliação de desempenho ambiental, sendo responsável pelas maiores possibilidades de pontuação, uma vez que questões como o consumo de água, energia e materiais são consideradas de grande impacto para a determinação do desempenho ambiental de um edifício. Portanto, todas as certificações em análise nesse trabalho possuem categorias referentes ao consumo de recursos.

Iniciando nossa análise na certificação GBTool, o item "Quantidade e qualidade dos materiais externos utilizados", assim como "Materiais de baixo impacto", no Green Globes, demonstram falta de flexibilidade ao contexto regional brasileiro por se tratarem de créditos que ficam submetidos à utilização de materiais certificados, alguns dos quais ainda são de difícil acesso no mercado brasileiro. Da mesma forma, na categoria Materiais e Recursos, do LEED for Homes, encontramos, no crédito "Materiais Ambientalmente Preferíveis" a mesma dificuldade 


\begin{tabular}{|c|c|c|c|}
\hline $\begin{array}{l}\text { Créditos Avaliativos Inadequados ao contexto } \\
\text { brasileiro (por Categorias) }\end{array}$ & $\begin{array}{l}\text { Sistema de } \\
\text { Certificação }\end{array}$ & Naturezada inadequação & $\begin{array}{l}\text { Possibilidade de } \\
\text { Adaptação }\end{array}$ \\
\hline \multicolumn{4}{|l|}{ Categoria Conexões } \\
\hline $\begin{array}{l}\text { Certificação LEED para o desenvolvimento de } \\
\text { rros }\end{array}$ & LEED for Homes & Aplicabilidade / Flexibilidade regional & $\mathrm{D}$ \\
\hline \multicolumn{4}{|l|}{ Categoria Implantação } \\
\hline Efeito local de ilha de calor & LEED for Homes & Aplicabilidade / Flexibilidade regional & $B$ \\
\hline Controle não tóxico de pestes & LEED for Homes & Aplicabilidade / Flexibilidade regional & c \\
\hline Desenvolvimento compacto & LEED for Homes & Adequação à normatização estudada & B \\
\hline \multicolumn{4}{|l|}{ Categoria Emissões } \\
\hline $\begin{array}{l}\text { Emissão de substâncias destruidoras da camada } \\
\text { de ozônio }\end{array}$ & GBTool & Aplicabilidade / Flexibilidade regional & C \\
\hline Emissões atmosféricas & Green Globes & Aplicabilidade ao contexto brasileiro & B \\
\hline Destruição da camada de ozônio & Green Globes & Aplicabilidade / Flexibilidade regional & C \\
\hline Minimização da poluição & Green Globes & Aplicabilidade ao contexto brasileiro & B \\
\hline \multicolumn{4}{|l|}{ Categoria Consumo de Recursos } \\
\hline $\begin{array}{l}\text { Quantidade e qualidade dos materiais externos } \\
\text { utilizados }\end{array}$ & GBTool & Aplicabilidade / Flexibilidade regional & B \\
\hline Transporte eficiente energeticamente & Green Globes & Flexibilidade regional & B \\
\hline Conservação da água & Green Globes & Flexibilidade regional & B \\
\hline Tratamento local da água & Green Globes & Adequação à normatização estudada & B \\
\hline Materiais de baixo impacto & Green Globes & Aplicabilidade ao contexto brasileiro & B \\
\hline Uso interno de água & LEED for Homes & Aplicabilidade / Flexibilidade regional & B \\
\hline Produtos ambientalmente preferíveis & LEED for Homes & Aplicabilidade / Flexibilidade regional & B \\
\hline Otimização de consumo energético & LEED for Homes & Aplicabilidade / Flexibilidade regional & C \\
\hline Refrigeração residencial & LEED for Homes & Aplicabilidade / Flexibilidade regional & C \\
\hline \multicolumn{4}{|l|}{ Categoria Conforto e Qualidade Ambiental } \\
\hline Qualidade do ar e ventilação & GBTool & Aplicabilidade / Flexibilidade regional & $C$ \\
\hline Conforto Térmico & GBTool & Aplicabilidade / Flexibilidade regional & C \\
\hline Sistema de ventilação & Green Globes & Aplicabilidade / Flexibilidade regional & $c$ \\
\hline Conforto Térmico & Green Globes & Aplicabilidade / Flexibilidade regional & $c$ \\
\hline $\begin{array}{l}\text { Criação de condições de conforto higrotérmico } \\
\text { de inverno } \\
\text { Criação de condições de conforto higrotérmico } \\
\text { de verão em ambientes com sistema de } \\
\text { resfriamento artificial }\end{array}$ & AQUA & Aplicabilidade / Flexibilidade regional & $c$ \\
\hline Garantia de uma ventilação eficaz & AQUA & Aplicabilidade / Flexibilidade regional & C \\
\hline Energy Star com Pacote de ar interno & LEED for Homes & Aplicabilidade / Flexibilidade regional & $\mathrm{D}$ \\
\hline $\begin{array}{l}\text { Distribuição de Sistemas de Aquecimento e } \\
\text { Condicionamento } \\
\text { do Ar }\end{array}$ & LEED for Homes & Aplicabilidade / Flexibilidade regional & C \\
\hline Filtragem do ar & LEED for Homes & Aplicabilidade / Flexibilidade regional & $c$ \\
\hline Controle de contaminantes & LEED for Homes & Aplicabilidade / Flexibilidade regional & B \\
\hline Proteção contra Radônio & LEED for Homes & Aplicabilidade / Flexibilidade regional & $\mathrm{D}$ \\
\hline \multicolumn{4}{|l|}{ Categoria Serviços } \\
\hline Flexibilidade e adaptabilidade & GBTool & $\begin{array}{l}\text { Pertinência para determinação de } \\
\text { desempenho ambiental }\end{array}$ & $\mathrm{D}$ \\
\hline Privacidade e acesso à luz solar e vistas & GBTool & $\begin{array}{l}\text { Pertinência para determinação de } \\
\text { desempenho ambiental }\end{array}$ & $\mathrm{D}$ \\
\hline Qualidade de serviços e desenvolvimento local & GBTool & $\begin{array}{l}\text { Pertinência para determinação de } \\
\text { desempenho ambiental }\end{array}$ & $\mathrm{D}$ \\
\hline \multicolumn{4}{|l|}{ Categoria Aspectos Econômicos } \\
\hline Custos ao longo do ciclo de vida & GBTool & $\begin{array}{l}\text { Pertinência para determinação de } \\
\text { desempenho ambiental }\end{array}$ & $\mathrm{D}$ \\
\hline Custos de construção & GBTool & $\begin{array}{l}\text { Pertinência para determinação de } \\
\text { desempenho ambiental }\end{array}$ & $\mathrm{D}$ \\
\hline Custos de operação e manutenção & GBTool & $\begin{array}{l}\text { Pertinência para determinação de } \\
\text { desempenho ambiental }\end{array}$ & $\mathrm{D}$ \\
\hline \multicolumn{4}{|l|}{ Categoria Planejamento de Operação } \\
\hline Ajuste de desempenho & GBTool & Aplicabilidade / Flexibilidade regional & $C$ \\
\hline $\begin{array}{l}\text { Permanência do desempenho dos sistemas de } \\
\text { aquecimento e resfriamento }\end{array}$ & AQUA & Aplicabilidade / Flexibilidade regional & c \\
\hline
\end{tabular}

Figura 4: Tabela 04 - Inadequações dos sistemas de certificação estudados ao contexto brasileiro. Fonte: Autores. 
de aplicação. O crédito apresenta um conceito forte e válido que dá preferência ao uso de materiais produzidos e transformados em região próxima à edificação certificada, e que não apresente atividades agressoras ao meio ambiente, que deve ser mantido com as devidas adequações.

O item "Transporte eficiente energeticamente", encontrado na certificação Green Globes, também apresenta determinada dificuldade de aplicação, uma vez que o crédito pontua estratégias que facilitem o uso de transporte público ou cicloviário, e pode demonstrar inaplicabilidade para pequenas cidades, onde sistemas de transporte público podem ser inclusive inexistentes, ou realidades geográficas acidentadas, onde o uso da bicicleta não é viável.

Nas questões relativas ao consumo de água, também podemos encontrar dificuldades de aplicação no sistema Green Globes, nos itens referentes a "Conservação da água" e "Tratamento local de água", onde há divergências com a legislação e características regionais brasileiras. As estratégias sugeridas de escolha de plantas e paisagismo para diminuir a necessidade de irrigação possuem parâmetros de desempenho que não podem ser aplicados às regiões mais áridas do pais, por exemplo. Na certificação LEED for Homes, em relação aos créditos da categoria Eficiência de Água, apenas aquele referente ao "Uso Interno de Água" demonstra algumas não conformidades com a legislação brasileira, baseando seus padrões de consumo na norma americana ASME A112.19.14 (ASME, 2006).

A categoria Energia e Atmosfera é a que apresenta maior número de inconsistências de aplicabilidade de conceitos e padrões para a realidade brasileira. Dos créditos existentes e passíveis de aplicação, a grande maioria apresenta alguma fragilidade conceitual para aplicação no contexto brasileiro.

Primeiramente, o crédito referente a "Isolamento", sugerindo o isolamento de paredes, sistemas de abertura e cobertura, com o intuito de minimização de trocas de calor entre os ambientes internos e externo, não é adequado a países de clima tropical, onde na cultura construtiva, os materiais mais popularmente empregados não implicam nesse tipo de elementos isolantes, mais comuns em países de clima temperado.
Da mesma forma, diversos créditos dessa categoria versam sobre questões referentes a ambientes climatizados, com sistemas mecânicos de resfriamento e aquecimento, no entanto, no Brasil, a climatização mecânica, mesmo que de resfriamento, de edificações habitacionais não é uma prática comum, restringindose a residências de alto padrão, o que restringiria o cumprimento dos créditos apenas aos extratos mais abastados da sociedade.

No crédito referente ao uso e desempenho de aberturas horizontais e verticais, mais uma vez, os padrões utilizados como base para análise dos tamanhos indicados para tais aberturas, assim como os níveis ótimos de transmitância a serem escolhidos para os vidros de vedação, são baseados em normas que visam o conforto em regiões de clima temperado, mais apropriados para o contexto norte-americano, no qual se enfoca a certificação em estudo.

Todos os métodos dão importância significativa à emissão de CO2 durante a operação do edifício (o GBC considera também o CO2 incorporado aos materiais). Esta é claramente uma reação de países de clima frio (com demanda intensa por aquecimento) e/ou com matrizes energéticas baseadas no uso de combustíveis fósseis às metas de emissões de CO2 estabelecidas no Protocolo de Kioto. No caso brasileiro, o controle de CO2 durante a operação dos edifícios não é tão válida, uma vez que a necessidade de refrigeração dos ambientes é muito mais freqüente que de aquecimento; a eletricidade utilizada é, em sua maior parte, proveniente de fontes hidráulicas; e apenas uma parcela pequena do aquecimento de água provém de combustível fóssil (gás) e o uso de chuveiros elétricos ineficientes é dominante (SILVA et al, 2003).

No Brasil, a emissão de CO2 durante a produção dos materiais de construção pode ser preponderante em muitos casos e seria provavelmente mais eficiente implementar medidas de controle durante a produção, como a certificação de materiais e processos quanto à emissão de $\mathrm{CO} 2$, por exemplo (SILVA et al, 2003).

A categoria Conforto e Qualidade Ambiental engloba todos os créditos presentes nos sistemas de certificação apresentados que abordam temas relativos a conforto térmico, acústico, lumínico, ventilação, assim como questões de salubridade no 
ambiente construído. Todos os quatro sistemas de certificação de desempenho ambiental do edifício apresentam questões avaliativas relacionadas ao tema, sendo a certificação AQUA aquela que aborda o tema de forma mais abrangente e completa.

Dentro dos critérios de avaliação do grupo Conforto e Qualidade Ambiental, em todos os sistemas de certificação, diversos créditos assumem, mais uma vez, como pressuposto que os ambientes possuem equipamentos de climatização mecânica, que, como esclarecemos anteriormente não são comumente utilizados em edificações residenciais unifamiliares no contexto brasileiro. Entretanto, dentro desses créditos há também questões que podem ser abordadas, porém sob outros parâmetros de desempenho, no desenvolvimento de uma certificação para edificações habitacionais brasileiras.

Sabemos que em algumas regiões bioclimáticas brasileiras a utilização de sistemas de climatização mecânica se faz necessária, entretanto, essa não é uma prática generalizada para edificações habitacionais unifamiliares da maioria das regiões do país, portanto, pretendemos tratá-la como exceção para efeitos avaliativos. Portanto, aqui a análise de técnicas de utilização de ventilação natural, pouco enfocada nesta certificação, certamente seria mais apropriada para a certificação da qualidade do ar interno das edificações em estudo.

As abordagens referentes à categoria Qualidade de Serviços em um edifício raramente são abordadas dentro de um sistema de certificação ambiental. Isso porque, frequentemente, essas questões não são diretamente associadas ao desempenho ambiental do edifício. No entanto, é importante notar que algumas atividades relacionadas aos serviços, como a controlabilidade dos sistemas de ventilação e climatização, ou a manutenção de desempenho de tais sistemas, estão relacionadas ao desempenho ambiental do edifício uma vez que podem significar uma maior capacidade de controle sobre o conforto ambiental, consumo energético e conseqüentes emissões de $\mathrm{CO} 2$ do edifício.

Dos seis créditos apresentados nessa categoria, três não apresentam pertinência significativa para a determinação de desempenho ambiental de um edifício, sendo eles "Flexibilidade a adaptabilidade", "Privacidade e acesso à luz solar e vistas" e
"Qualidade de serviços e desenvolvimento local". Os parâmetros avaliativos presentes nesses três itens não apresentam qualquer relação com o consumo energético o conforto ambiental do usuário.

Quando tratamos do estudo de sustentabilidade do edifício, todas as questões de serviços, que seguem o viés social de definição desse conceito, são também imprescindíveis, entretanto, nesse trabalho, nos limitaremos ao estudo da avaliação de desempenho ambiental da edificação habitacional, não incluindo, portanto, abordagens sociais ou mesmo econômicas, como veremos também na próxima categoria de estudo.

A categoria Aspectos Econômicos, dedicada aos aspectos econômicos do edifício nas fases de construção, operação e manutenção, ou seja, ao longo de todo o seu ciclo de vida, da mesma forma que a categoria estudada no item anterior, seria mais pertinente à avaliação de sustentabilidade de um edifício do que do desempenho ambiental propriamente dito.

A categoria Planejamento de Operação está diretamente relacionada à participação direta dos operadores do edifício, seus usuários e administradores Ainda que sejam tratados sistemas substancialmente mecanizados e automatizados, a interferência do usuário está sempre presente e, por isso, deve também ser planejada e controlada dentro das possibilidades existentes. Os sistemas de certificação aqui estudados tratam, nessa categoria, de estágios diferentes do ciclo de vida do edifício podendo ser, futuramente, reagrupados para que possam trabalhar em conjunto. O único estágio da vida do edifício que não está tratado em nenhuma dessas certificações é a demolição, para a qual, deveria sim, ser prevista uma metodologia de ação.

Mais uma vez, da mesma forma que na primeira categoria estudada neste capítulo, referente ao processo de projeto, os itens avaliativos demonstramse bastante flexíveis e, portanto, facilmente aplicáveis em diferentes realidades regionais. Dentre todos os sistemas de certificação estudados os únicos que apresentaram inaplicabilidade de itens avaliativos para essa categoria foram GBTool e AQUA.

A despeito da aparente inviabilidade de alguns itens avaliativos das diversas categorias estudadas 
mediante aos critérios de balizamento, notamos que estes podem ainda ser adaptados para permanência num sistema de certificação brasileiro, uma vez que sofram algumas alterações conceituais que confiram a tais itens flexibilidade e capacidade de adaptação principalmente às questões normativas e regionais do país.

Finalmente, depois de analisada a aplicabilidade individual dos itens avaliativos para cada sistema de certificação de desempenho ambiental estudado nesse trabalho, passaremos a um processo de reagrupamento e reconsideração de cada um desses itens, a fim de possibilitar a estruturação de um sistema de certificação ambiental para edificações habitacionais brasileiras.

\section{Discussão das inadequações e proposição de alternativas de adaptação}

Dos créditos avaliativos considerados inadequados para aplicação em edificações habitacionais no contexto brasileiro, são poucas as situações onde esses demonstram total inaplicabilidade. Na maioria dos casos, tais créditos necessitam apenas de algum tipo de adequação em seus critérios avaliativos, de forma a serem adaptados ao contexto de aplicação desejado.

Na primeira categoria estudada neste trabalho, Conexões, foi encontrado apenas um único crédito avaliativo o qual demonstrou alguma inadequação ao contexto brasileiro: "Certificação LEED para o desenvolvimento de Bairros". Tal crédito apresentou inadequações aos critérios de balizamento "aplicabilidade ao contexto brasileiro" e "flexibilidade regional", os quais estão intimamente ligados em seus conceitos, devido ao fato de que o LEED para o Desenvolvimento de Bairros não se verifica amplamente difundido no país. No entanto, a certificação LEED for Homes, a qual apresenta tal crédito avaliativo, oferece também outras possibilidades de cumprimento de créditos sem o uso de tal certificação, o que minimiza a problemática da inadequação de tal crédito, o qual pode ser simplesmente excluído, sem grandes danos ao conceito avaliativo do sistema.

Na categoria seguinte, Implantação, são três os créditos avaliativos os quais apresentam inadequações de aplicação, sendo estes: Efeitos local de ilha de calor, Controle não-tóxico de pestes e Desenvolvimento compacto, todos os três, mais uma vez, pertencentes ao sistema de certificação LEED for Homes.

O crédito "Efeito Local de Ilha de Calor", o qual demonstra restrição regional de aplicação, demonstrando-se claramente direcionado a habitações localizadas no hemisfério norte quando considera o solstício de verão em 21 de junho, poderia muito facilmente se tornar aplicável ao contexto brasileiro apenas se mudando tal diretriz de avaliação para o solstício de verão no hemisfério sul (21 de dezembro). Esta simples mudança de critério torna o crédito perfeitamente aplicável ao contexto brasileiro.

Dentro da mesma categoria, o crédito referente ao "Controle não-tóxico de pestes", traz uma série de recomendações quanto a construções em madeira, as quais não são largamente comuns no contexto geral brasileiro, a não ser por algumas exceções regionais, principalmente na região sul do país. A aplicação de tal crédito poderia ser considerada com pontuação ponderável a diferentes tipos de edificação, sendo incorporadas, por exemplo, pontuações extras e específicas referentes às características regionais do projeto. No entanto, tal questão também não se demonstra de grande pertinência para determinação de desempenho ambiental da edificação, o que atribui ao crédito um caráter complementar, e não necessário

Quanto à não adequação à legislação vigente do item referente ao desenvolvimento compacto, é importante esclarecer que não se trata de uma incompatibilidade rígida, ou seja, a adequação fica dependente dos zoneamentos urbanos locais, e sua densidade construtiva máxima permitida, como salientado no capítulo anterior.

Dos créditos apresentados como inadequados à aplicação no contexto brasileiro da categoria Consumo de Recursos, aqueles referentes ao uso materiais certificados, como "Quantidade e qualidade dos materiais externos utilizados", da certificação GBTool, "Materiais de baixo impacto", da certificação Green Globes, e "Produtos Ambientalmente Preferíveis", do LEED for Homes, foram assim considerados devido à sua inadequação aos critérios de balizamento referentes à aplicabilidade ao contexto brasileiro e 
flexibilidade de regional, uma vez que a certificação ambiental de componentes construtivos ainda não é prática corrente no país, exceto pela certificação de madeiras.

A classificação e certificação de materiais e componentes construtivos ainda demonstrase como uma prática embrionária, em fase de desenvolvimento inicial, devido à escassez de dados sobre a origem de matérias primas, processos e recursos empregados para a produção de tais componentes. Atualmente, os sistemas de certificação avaliam o desempenho ambiental de materiais de construção majoritariamente pelo reconhecimento de atributos do produto, tais como custo, durabilidade, renovabilidade e conteúdo reciclado. Esta abordagem lida com tais atributos, sozinho, quando na verdade eles são muitas vezes em conflito e interferindo uns com os outros (SILVA, 2007). Por esta razão, a abordagem por atributos perde o senso do impacto holístico de um produto.

Diante das pesquisas sobre o estado da arte deste tema, conclui-se que a solução para tal problema estaria no desenvolvimento de uma metodologia específica de avaliação de ciclo de vida de componentes construtivos, a qual, com a difusão de sua aplicação, possibilitaria a criação de um banco de dados de inventários de ciclo de vida de tais produtos, de forma que estes poderiam ser comparados de forma a levar à escolha do produto mais adequado às necessidades construtivas e prerrogativas ambientais do edifício em questão.

Uma tentativa nesse sentido são as EDPs (Declaração Ambiental de Produtos) as quais foram desenvolvidas, de acordo com a complexidade dos resultados da ACV, para padronizar a coleta de dados de inventário de diversos produtos, e que têm sido usadas também para materiais e componentes da construção. As EPDs são padronizadas pelas normas europeias EN 15804 (CEN, 2012) e EN 15978 (CEN, 2011).

O item "Transporte eficiente energeticamente", da certificação Green Globes, apresenta dificuldade de aplicação do ponto de vista da flexibilidade regional, uma vez que pontua estratégias que incentivam o uso de transporte público ou cicloviário, podendo demonstrar inaplicabilidade para pequenas cidades ou realidades geográficas acidentadas, conforme observado no capítulo anterior. Segundo os estudos realizados nesse trabalho, a melhor alternativa para aplicação de um crédito a partir do conceito de transporte eficiente, seria a flexibilização dos critérios avaliativos, de forma que sejam inicialmente estudadas as alternativas viáveis de utilização de meios de transporte eficientes energeticamente na região onde o edifício será implantado, para então avaliar a boa utilização de tais alternativas pelo edifício.

Nas questões relativas ao consumo de água, também podemos encontrar dificuldades de aplicação no contexto brasileiro dos itens presentes nos sistemas de certificação, como no sistema Green Globes, nos itens referentes a "Conservação da água" e "Tratamento local de água", podemos notar divergências com a legislação brasileira, assim como inadequações de aplicabilidade ao contexto brasileiro, da mesma forma que na certificação LEED for Homes, o item referente ao Uso Interno de Água, o qual baseia seus padrões de consumo na norma americana ASME A112.19.14 (2006), e recomenda o uso de equipamentos sanitários com selo de desempenho do U.S. EPA WaterSense. O que podemos notar nesses itens avaliativos não é uma inadequação conceitual, e sim de parâmetros. Portanto, para legitimar a aplicabilidade de tais créditos é necessário tão somente que seus parâmetros avaliativos sejam alterados e baseados na legislação brasileira, o que tornaria todos os três itens citados acima perfeitamente aplicáveis.

O crédito relativo à "Otimização de Consumo Energético", apresentado pela certificação LEED for Homes, é o que apresenta maior número de inconsistências de aplicabilidade de conceitos e padrões para a realidade brasileira. Quando se trata do consumo de recursos energéticos e, desta forma, já se fazendo conexão com algumas questões de qualidade do ambiente interno, a principal causa da inaplicabilidade dos créditos refere-se à utilização de climatização mecânica de ambientes, a qual não demonstra-se largamente utilizada em unidades habitacionais brasileiras, principalmente aquelas de baixo custo, ou localizadas em regiões menos quentes do país.

Dentro dos critérios de avaliação do grupo Qualidade Ambiental Interna, os itens "Qualidade do ar e ventilação" e "Conforto térmico" da certificação GBTool, assumem como pressuposto que os 
ambientes possuem equipamentos de climatização mecânica, da mesma forma que a certificação Green Globes também pressupõe ventilação mecânica em seus créditos referentes ao "Sistema de Ventilação", assim como os créditos "Criação de condições de conforto higrotérmico de inverno", "Criação de condições de conforto higrotérmico de verão com resfriamento artificial" e "Garantia de uma ventilação eficaz", no sistema AQUA. A mesma situação de priorização da avaliação de sistemas mecânicos de condicionamento acontece nos itens "Distribuição de Sistemas de Aquecimento e Condicionamento do $\mathrm{Ar}^{\prime \prime}$ e seus sistemas de filtragem, da certificação LEED for Homes.

Sabemos que em algumas regiões bioclimáticas brasileiras a utilização de sistemas de climatização mecânica se faz necessária, entretanto, essa não é uma prática generalizada para edificações habitacionais unifamiliares da maioria das regiões do país, portanto, pretendemos tratá-la como exceção para efeitos avaliativos. A aplicação de tais créditos poderia ser considerada com pontuação ponderável a diferentes tipos de edificação e localização, sendo incorporados, por exemplo, a pontuações extras e específicas referentes às características regionais do projeto, como sugerido para o item relativo ao controle não tóxico de pestes.

Além disso, para o contexto brasileiro a análise de técnicas de utilização de ventilação natural, pouco enfocada nas certificações estudadas, certamente seria mais apropriada para a certificação da qualidade do ar interno das edificações em estudo.

O item "Conforto Térmico", da certificação Green Globes, não pode ser aplicado ao contexto brasileiro atualmente por basear seus parâmetros de desempenho térmico na norma americana ASHRAE 55 (ASHRAE, 2004), inadequação que poderia ser facilmente resolvida com a alteração dos parâmetros avaliativos de tal crédito, passando à utilização da normatização brasileira em vigor.

Finalmente, na categoria Qualidade do Ambiente Interno, a utilização da certificação Energy Star para residências, como um caminho para cumprimento dos créditos, demonstra-se inadequada, pela dificuldade de aplicação no contexto brasileiro, o que deve resultar em sua exclusão do processo avaliativo, e substituição pelos próprios créditos sugeridos pelo sistema de certificação em questão. Tal dificuldade de aplicação se justifica, principalmente pelo estabelecimento de parâmetros de desempenho energético baseados na legislação norte-americana. No caso brasileiro, a indicação mais apropriada para a substituição direta do selo Energy Star seria a utilização do selo RTQ-R (Requisitos Técnicos da Qualidade para o Nível de Eficiência Energética em Edifícios) do programa Procel Edifica (BRASIL, 2010).

Quanto à questão das Emissões, tratada em categoria própria, como já discutido anteriormente neste trabalho, todos os métodos dão importância significativa à emissão de $\mathrm{CO} 2$ durante a operação do edifício, demonstrando incoerência com o cenário brasileiro, onde o controle de $\mathrm{CO} 2$ durante a operação dos edifícios não é prioritária, uma vez que a necessidade de refrigeração dos ambientes é muito mais freqüente que de aquecimento e a eletricidade utilizada é, em sua maior parte, proveniente de fontes hidráulicas.

No sistema de certificação Green Globes o item referente a emissões atmosféricas tem seu critério de desempenho baseado na norma ASME A112.19.14 (2006), o que, para aplicação no contexto brasileiro, deve sofrer alteração em seus parâmetros avaliativos, que devem ser baseados na legislação brasileira vigente.

Ainda no Green Globes, assim como GBTool, os itens que versam sobre a "Destruição da Camada de Ozônio", e "Emissão de substâncias destruidoras da camada de ozônio", respectivamente, abordam, mais uma vez, questões referentes a ambientes climatizados, podendo ser aplicada para esses créditos a mesma alternativa proposta para casos semelhantes, analisados nas categorias anteriores. O tópico relativo à "Minimização da poluição" advinda do edifício, apresenta algumas inadequações relativas à normatização em que o crédito se baseia, mostrando-se necessária a substituição desta pela normatização brasileira adequada.

Na categoria Serviços, os créditos "Flexibilidade e adaptabilidade", "Privacidade e acesso à luz solar e vistas" e "Qualidade de serviços e desenvolvimento local", não apresentam pertinência significativa para a determinação de desempenho ambiental de um edifício, uma vez que os parâmetros avaliativos 
presentes nesses três itens não apresentam relação com o consumo energético ou o conforto ambiental do usuário, portanto, a sua exclusão não implicará em nenhuma forma no comprometimento da estrutura avaliativa. O mesmo dá-se com os créditos da categoria Aspectos Econômicos, visto que, neste trabalho, nos limitamos ao estudo da avaliação de desempenho ambiental da edificação habitacional, não incluindo abordagens sociais ou econômicas.

Dentre todos os sistemas de certificação estudados, apresentaram inadequação à categoria Planejamento de operação a certificação GBTool, no item relativo ao "Ajuste de Desempenho" e a certificação AQUA, no item "Permanência do desempenho dos sistemas de aquecimento e resfriamento", ambos baseados em critérios avaliativos diretamente relacionados a sistemas de refrigeração e aquecimento automatizados. Mais uma vez, a proposta aqui é a avaliação do planejamento de operação de tais equipamentos de forma complementar, uma vez seja constatada a sua existência no edifício a ser avaliado.

Os sistemas de certificação estudados neste trabalho tratam, nesta última categoria, de estágios diferentes do ciclo de vida do edifício, podendo ser, futuramente, reagrupados para que possam trabalhar em conjunto. O único estágio da vida do edifício que não é abordado em nenhuma dessas certificações é a demolição, ou desmonte, para a qual, deveria sim, ser prevista uma metodologia de operação.

A Tabela 05 apresenta um quadro sinóptico das possibilidades de adaptação dos créditos considerados inadequaldos pela análise comparativa, de forma a sintetizar a discussão de aplicabilidade.

\section{Conclusões}

A conclusão final da análise comparativa desenvolvida nesta pesquisa é que o sistema de certificação de desempenho ambiental AQUA demonstra ser a ferramente mais adequada para avaliação de edifícios no contexto brasileiro.

É importante salientar que, do ponto de vista da metodologia de aplicação, o sistema AQUA apresenta nuances bastante específicas, uma vez que sua estruturação em questionário aplicado por terceiros e sua adaptação ao contexto brasileiro deveriam tornar este o método mais fortemente aplicado no panorama atual. Entretanto, a falta de divulgação em torno dessa certificação, combinada com os altos custos do processo tem, até o presente momento, restringido o número de aplicações desta ferramenta.

Por outro lado, a menor complexidade de aplicação da metodologia LEED for Homes torna esta mais popular, e portanto, mais atraente para aplicação. Sendo assim, a utilização dos créditos e critérios da metodologia AQUA organizados num sistema de avaliação em forma de checklist, baseado na metodologia LEED for Homes, seria um bom início para o desenvolvimento de um sistema de certificação de desempenho ambiental de edificações residenciais no contexto brasileiro.

A partir da análise comparativa e balizamento de itens avaliativos das certificações estudadas pelos critérios preestabelecidos neste trabalho, assim como pela discussão da aplicabilidade de tais critérios no contexto brasileiro, é possível afirmar que as ferramentas estudadas demonstram uma série de itens avaliativos plenamente aplicáveis a edifícios residenciais situados no cenário brasileiro e outros que ainda necessitam de adaptações.

O sistema de certificação que apresentou o maior número de inadequações foi o LEED for Homes, no entanto, de seus 13 créditos inadequados, apenas um demonstrou-se completamente inaplicável, ao passo que o sistema de certificação GBTool, a despeito de ter apresentado um número menor de inadequações (dez), possui um maior número de inaplicabilidades, somando, ao todo, seis créditos inaplicáveis.

O sistema de certificação AQUA foi o que demonstrou menor número de inadequações para aplicação no contexto brasileiro (apenas quatro), sendo que todas elas apresentam-se em créditos que poderiam ter cumprimento opcional, dependentemente da região brasileira de aplicação da certificação (como demonstrado na Tabela 19, do capítulo anterior).

As limitações regionais de aplicação estudadas neste trabalho remetem, em sua maioria, à ineficiência da aplicação de certificações internacionais fora do contexto em que tiveram baseado sua criação 


\begin{tabular}{|c|c|c|}
\hline $\begin{array}{l}\text { Créditos Avaliativos Inadequados ao } \\
\text { contexto brasileiro } \\
\text { (por Categorias) }\end{array}$ & Sistema de Certificação & Estratégia de Adaptação \\
\hline \multicolumn{3}{|l|}{ Categoria Implantação } \\
\hline Efeito local de ilha de calor & LEED for Homes & $\begin{array}{l}\text { Utilização do solstício de verão variável de acordo com a latitude } \\
\text { do edifício }\end{array}$ \\
\hline Controle não tóxico de pestes & LEED for Homes & $\begin{array}{c}\text { Considerar crédito de pontuação extra para características de } \\
\text { caráter regional }\end{array}$ \\
\hline Desenvolvimento compacto & LEED for Homes & Flexibilidade em relação ao zoneamento local do edifício \\
\hline \multicolumn{3}{|l|}{ Categoria Emissões } \\
\hline $\begin{array}{l}\text { Emissão de substâncias destruidoras da camada } \\
\text { de ozônio }\end{array}$ & GBTool & $\begin{array}{c}\text { Considerar créditos sobre ambientes climatizados de pontuação } \\
\text { extra para características de caráter regional }\end{array}$ \\
\hline Emissões atmosféricas & Green Globes & Parametrização do crédito pela legislação brasileira em vigor \\
\hline Destruição da camada de ozônio & Green Globes & $\begin{array}{c}\text { Considerar créditos sobre ambientes climatizados de pontuação } \\
\text { extra para características de caráter regional }\end{array}$ \\
\hline Minimização da poluição & Green Globes & Parametrização do crédito pela legislação brasileira em vigor \\
\hline \multicolumn{3}{|l|}{ Categoria Planejamento de Operação } \\
\hline Ajuste de desempenho & GBTool & $\begin{array}{c}\text { Considerar créditos sobre ambientes climatizados de pontuação } \\
\text { extra para características de caráter regional }\end{array}$ \\
\hline $\begin{array}{l}\text { Permanência do desempenho dos sistemas de } \\
\text { aquecimento e resfriamento }\end{array}$ & AQUA & $\begin{array}{c}\text { Considerar créditos sobre ambientes climatizados de pontuação } \\
\text { extra para características de caráter regional }\end{array}$ \\
\hline \multicolumn{3}{|l|}{ Categoria Consumo de Recursos } \\
\hline $\begin{array}{l}\text { Quantidade e qualidade dos materiais externos } \\
\text { utilizados }\end{array}$ & GBTool & Avaliação através de inventários de ciclo de vida \\
\hline Transporte eficiente energeticamente & Green Globes & $\begin{array}{c}\text { Considerar crédito de pontuação extra para características de } \\
\text { caráter regional }\end{array}$ \\
\hline Conservação da água & Green Globes & Parametrização do crédito pela legislação brasileira em vigor \\
\hline Tratamento local da água & Green Globes & Parametrização do crédito pela legislação brasileira em vigor \\
\hline Materiais de baixo impacto & Green Globes & Avaliação através de inventários de ciclo de vida \\
\hline Uso interno de água & LEED for Homes & Parametrização do crédito pela legislação brasileira em vigor \\
\hline Produtos ambientalmente preferíveis & LEED for Homes & Avaliação através de inventários de ciclo de vida \\
\hline Otimização de consumo energético & LEED for Homes & $\begin{array}{c}\text { Considerar créditos sobre ambientes climatizados de pontuação } \\
\text { extra para características de caráter regional }\end{array}$ \\
\hline Refrigeração residencial & LEED for Homes & $\begin{array}{c}\text { Considerar créditos sobre ambientes climatizados de pontuação } \\
\text { extra para características de caráter regional }\end{array}$ \\
\hline \multicolumn{3}{|l|}{ Categoria Conforto e Qualidade Ambiental } \\
\hline Qualidade do ar e ventilação & GBTool & $\begin{array}{c}\text { Considerar créditos sobre ambientes climatizados de pontuação } \\
\text { extra para características de caráter regional }\end{array}$ \\
\hline Conforto Térmico & GBTool & $\begin{array}{c}\text { Considerar créditos sobre ambientes climatizados de pontuação } \\
\text { extra para características de caráter regional }\end{array}$ \\
\hline Sistema de ventilação & Green Globes & $\begin{array}{c}\text { Considerar créditos sobre ambientes climatizados de pontuação } \\
\text { extra para características de caráter regional }\end{array}$ \\
\hline $\begin{array}{l}\text { Criação de condições de conforto higrotérmico } \\
\text { de inverno }\end{array}$ & AQUA & $\begin{array}{c}\text { Considerar créditos sobre ambientes climatizados de pontuação } \\
\text { extra para características de caráter regional }\end{array}$ \\
\hline $\begin{array}{l}\text { Criação de condições de conforto higrotérmico } \\
\text { de verão em ambientes com sistema de } \\
\text { resfriamento artificial }\end{array}$ & AQUA & $\begin{array}{c}\text { Considerar créditos sobre ambientes climatizados de pontuação } \\
\text { extra para características de caráter regional }\end{array}$ \\
\hline Garantia de uma ventilação eficaz & AQUA & $\begin{array}{c}\text { Considerar créditos sobre ambientes climatizados de pontuação } \\
\text { extra para características de caráter regional }\end{array}$ \\
\hline $\begin{array}{l}\text { Distribuição de Sistemas de Aquecimento e } \\
\text { Condicionamento do } \mathrm{Ar}\end{array}$ & LEED for Homes & $\begin{array}{c}\text { Considerar créditos sobre ambientes climatizados de pontuação } \\
\text { extra para características de caráter regional }\end{array}$ \\
\hline Filtragem do ar & LEED for Homes & $\begin{array}{c}\text { Considerar créditos sobre ambientes climatizados de pontuação } \\
\text { extra para características de caráter regional }\end{array}$ \\
\hline Controle de contaminantes & LEED for Homes & $\begin{array}{c}\text { Considerar créditos sobre ambientes climatizados de pontuação } \\
\text { extra para características de caráter regional }\end{array}$ \\
\hline
\end{tabular}

Figura 5: Tabela 05 - Estratégias de adaptação dos créditos considerados inadequados. 
e desenvolvimento. No entanto a adaptação dos critérios e parâmetros avaliativos utilizados pelas certificaçòes estudadas demonstrou-se possível através do estudo de adaptação das inaplicabilidades apresentado, o qual buscou a proposição de alternativas de adaptação de questões geográficas, climáticas, culturais e normativas.

Além disso, como a complexidade de aplicação das ferramentas demonstrou, neste trabalho, ser preponderante em sua aplicabilidade, o desenvolvimento de uma nova certificação deve considerar profundamente sua metodologia de aplicação, de forma que a flexibilidade regional defendida neste trabalho não venha tornar o sistema complexo demais para utilização pelos profissionais da área.

\section{Referências bibliográficas}

AMERICAN SOCIETY OF MECHANICAL ENGINEERS (ASME). A112.19.14 - Six-Liter Water Closets Equipped with a Dual Flushing Devic, 2006.

BRASIL, Ministério de Minas e Energia. Manual pra aplicação dos regulamentos:RTQ-C e RAC-C. Brasília, MME, 2010, 4v. Disponível em: <http://www.labeee. ufsc.br/projetos/etiquetagem $>$.

BUENO, C. Avaliação de desempenho ambiental de edificações habitacionais: Análise comparativa dos sistemas de certificação no contexto brasileiro. Dissertação de Mestrado apresentada ao Departamento de Arquitetura e Urbanismo da Escola de Engenharia de São Carlos da Universidade de São Paulo. São Carlos, 2010

CAIXA ECONÔMICA FEDERAL. Selo Casa Azul: Boas Práticas para Habitação Mais Sustentável. Guia Caixa Sustentabilidade Ambiental, 2010

COLE, R. J., LARSSON, N. Green Building Challenge 2002: GBTool User Manual. 2002.

FOSSATI, M. Metodologia para Avaliação da Sustentabilidade de Projetos de Edifícios: O Caso de Escritórios em Florianópolis. Tese de Doutorado. Programa de Pós-graduação em Engenharia Civil, Universidade Federal de Santa Catarina, 2008.

EUROPEAN COMMITTEE FOR STANDARDIZATION (CEN), 2012. European Standard EN 15804: Sustainability of construction works - Environmental product declarations - Core rules for the product category of construction products.

EUROPEAN COMMITTEE FOR STANDARDIZATION (CEN), 2011. European Standard EN 15978: Sustainability of construction works - Assessment of environmental performance of buildings - Calculation method in your references.

FUNDAÇ̃̃O CARLOS ALBERTO VANZOLINI. Referencial Técnico de Certificação: Edifícios do Setor de Serviços - Processo AQUA. 2007. Disponível em: <http://www.geaconstruction.com/ arquivos/HQE \% 20FCAV\% $202007 \% 20 \% 20$ Completo\%2015\%2010\%2007\%20v21\%20 sem \%20revisões\%20-rm2-ca..pdf>. Acessado em: 11.set.2008

PARDINI, A. F. Contribuição ao entendimento da certificação LEED e do conceito de custos no ciclo de vida em empreendimentos mais sustentáveis no Brasil. Dissertação de Mestrado. Faculdade de Engenharia Civil, Arquitetura e Urbanismo, Universidade Estadual de Campinas, 2009

PATRICIO, R. M. R.; GOUVINHAS, R. P. Avaliação de Desempenho Ambiental em Edificações: Diretrizes para o Desenvolvimento de uma nova metodologia adaptada à realidade do Nordeste. In: I Conferência Latino-Americana de Construção Sustentável $/ 10^{\circ}$ Encontro Nacional de Tecnologia do Ambiente Construído, 2004, São Paulo. $10^{\circ}$ Encontro Nacional de Tecnologia do Ambiente Construído, 2004

PICCOLI, R.; KERN, A. P.; GONZÁLEZ, M. A.; HIROTA, E. H. A certificação de desempenho ambiental de prédios: exigências usuais e novas atividades na gestão da construção. Ambiente Construído, Porto Alegre, v. 10, n. 3, p. 69-79, jul./set. 2010

SILVA, V. G. Avaliação da sustentabilidade de edifícios de escritórios brasileiros: diretrizes e base metodológica. Tese (Doutorado em Engenharia Civil). Escola Politécnica da Universidade de São Paulo, Departamento de Engenharia de Construção Civil. São Paulo, 2003. 210p.

SILVA, V. G.; SILVA, M. G.; AGOPYAN, V. Avaliação de edifícios no Brasil: da avaliação ambiental para avaliação de sustentabilidade. Revista Ambiente Construído, Porto Alegre, v. 3, n. 3, p. 7-18, jul./set. 2003

SKOPEK, J. BREEAM, A Building Environmental Performance Assessment Method. In: Ontario Association of Architects Committee on the Environment. Canadá, 1997.

SKOPEK, J.; BRYAN, H. Green Globes: and online assessment tool for benchmarking building performance. Canadá, 2002

US GREEN BUILDING COUNCIL (USGBC). LEED (Leadership and Energy \& Environmental Design): Green Building Rating System - Version 3. Janeiro, 2009

US GREEN BUILDING COUNCIL (USGBC). LEED for Homes Rating System. Janeiro 2008.

VOSGUERITCHIAN, A. B. A abordagem dos sistemas de avaliação de sustentabilidade da arquitetura nos quesitos ambientais de energia, materiais e água, e suas associações às inovações tecnológicas. Dissertação de Mestrado. Faculdade de Arquitetura e Urbanismo, Universidade de São Paulo, 2006.

\section{Agradecimentos}

Este trabalho foi apoiado pela CAPES (Coordenação de Aperfeiçoamento de Pessoal de Nível Superior) e FINEP (Financiadora de Estudos e Projetos). 